\title{
Indian Journal of Medical Ethics
}

\author{
Published by the Forum for Medical Ethics Society, Mumbai 400025, India
}

The Code of Hammurabi and the Hippocratic Oath are testimony that medical ethics has been in existence as long as medicine has. The advances in science and medicine have taken some unexpected turns, creating more uncertainties and increasing concern about the ethical aspects of these advances. Journals for medical professionals and scientists such as the Journal of Medical Ethics (JME) published by BMJ Publications, the Bulletin of Medical Ethics and Eubios Journal of Asian and International Bioethics (EJAIB) address issues on medical ethics pertaining to industrialised countries quite comprehensively. But ethics is global, and there is a need to address regional issues specific to south Asia. The Indian Journal of Medical Ethics (IJME) seems to be the only journal focusing on medical ethics in south Asia.

The IJME was first published in 1993 under the name Medical Ethics, and changed to Issues in Medical Ethics from 1995. The name was changed again to Indian Journal of Medical Ethics from January 2004, giving it an identity. It is available online as www.issuesinmedica lethics.org. The IJME attempts to focus on the common ethical problems of south Asia, where resources are constrained, problems are many, and development and welfare priorities conflict more acutely than in more prosperous countries.

The IJME's coverage is comprehensive. It addresses a wide variety of current issues relevant to the SAARC region, from rights of the individual (e.g. informed consent, confidentiality, medical negligence) to ethical responsibility to the community. If you are a medical professional concerned about the intellectual "brain drain" to greener pastures, poverty, gross inequity of resource distribution and the access to health care, the $I J M E$ would give you a good dose of these. The IJME also focuses on organised criminal activity in relation to organ transplants, a characteristically regional issue, and exploitation of developing countries by the pharmaceutical industry for human clinical research. The $I J M E$ tends to dwell too much on negative aspects, compared with $J M E$ and $E J A I B$. India is a huge country with a resplendent history, and its rapid advances in science and technology must surely have absorbed some aspects of traditional ethical values that deserve praise? Is south Asia entirely a negative thinking region? Surely not. A little more constructive approach could balance things out.

The sequence is organised and reader friendly. Regular features include editorials written by experts and original articles. Previously published articles that are considered important are reprinted. Articles are categorised under topics such as controversy, viewpoint, discussion and selected summary. A refreshing book or film review lightens the way. The well balanced review, such as that on the Indian comedy film titled, "Munnabhai MBBS" in a recent issue (April-June 2004; 1, 2: 61), which depicts the underlying problems on the education of medical graduates in India, is delightful reading.

The editorial board's contribution of "From the Press" is a collection of thought provoking news reports on ethical issues, e.g. trade union action by doctors (JanMar 2004; 1, 1:6 and April-June 2004; 1, 2:40). "From other journals" gives the reader a bird's eye view of ethical issues from other publications. Correspondence provides a forum for critical discussion. The back cover is dedicated to updating the reader on the activities of the Forum for Medical Ethics Society, which owns and publishes the journal.

References are appropriate. The cover pictures are excellent. However, the lack of illustrations in the text seems to be a shortcoming, because articles conjure up a variety of images in the mind of an imaginative reader.

Overall, the $I J M E$ covers in depth a wide range of issues in medical ethics pertaining to the south Asian region. The format and content are focused, capture readers' interest, stimulate critical thinking and generate some colourful mental images. IJME is recommended for doctors, medical students, nurses and professionals in fields related to medicine. It deserves a wider readership, so that the region's ethical concerns and experiences could be shared.

Aroona Abdulla, Temporary Lecturer and Rohini Fernandopulle, Senior Lecturer, Department of Pharmacology, Faculty of Medicine, University of Colombo, Sri Lanka.

Correspondence: AA, e-mail: <iaroona@hotmail.com>. 